\title{
Teaching Conflicts of Interest and Shared Decision-Making to Improve Risk Communication: a Randomized Controlled Trial
}

\author{
Cora Koch, Dr ${ }^{1,2}$, Nadine Dreimüller, $\mathrm{Dr}^{7}$, Janosch Weißkircher, MSc ${ }^{7}$, Nicole Deis ${ }^{3}$, \\ Eva Gaitzsch, Dr ${ }^{3}$, Stefanie Wagner, Dr ${ }^{7}$, Marlene Stoll, MSc ${ }^{7}$, Franziska Bäßler, DH, \\ Klaus Lieb, Prof ${ }^{7}$, and Jana Jünger, Prof ${ }^{5}$
}

'Department of Psychiatry and Psychotherapy, University Medical Center Mainz, Mainz, Germany; ${ }^{2}$ Department of Neurology and Neurophysiology, University Medical Center Freiburg, Freiburg, Germany; ${ }^{3}$ Department of Pneumology, Thoraxklinik Heidelberg, Heidelberg University Hospital, Heidelberg, Germany; ${ }^{4}$ Department for General Internal and Psychosomatic Medicine, Heidelberg University Hospital, Heidelberg, Germany; ${ }^{5}$ IMPP - German Institute for Medical and Pharmaceutical Examinations, Mainz, Germany.

\begin{abstract}
BACKGROUND: Risk communication is a core aspect of a physician's work and a fundamental prerequisite for successful shared decision-making. However, many physicians are not able to adequately communicate risks to patients due to a lack of understanding of statistics as well as inadequate management of conflicts of interest (COI).
\end{abstract}

OBJECTIVE: To evaluate the effects of an integrated curriculum encompassing $\mathrm{COI}$ and shared decision-making on the participants' risk communication competence, that is, their competence to advise patients on the benefits and harms of diagnostic or therapeutic interventions.

DESIGN: A rater-blind randomized controlled trial with a 30 ( \pm 1$)$-week follow-up conducted from October 2016 to June 2017 at two German academic medical centers.

PARTICIPANTS: Sixty-three medical students in their fourth or fifth year.

INTERVENTIONS: Participants received either a newly developed 15-h curriculum or a course manual adapted from teaching as usual.

MAIN MEASURES: Primary outcome: change in risk communication performance in a video-observed structured clinical examination (VOSCE).

KEY RESULTS: Participants were 25.7 years old on average (SD 3.6); 73\% (46/63) were female. Increase in risk communication performance was significantly higher in the intervention group with post-intervention Cohen's $d$ of 2.35 (95\% confidence interval (CI) 1.62 to $3.01, p<0.01$ ) and of 1.83 (CI 1.13 to $2.47, p<0.01) 30( \pm 1)$ weeks later. Secondary outcomes with the exception of frequency of interactions with the pharmaceutical industry also showed relevant improvements in the intervention as

Cora Koch and Nadine Dreimüller contributed equally to this paper. Prof. Klaus Lieb and Prof. Jana Jünger also contributed equally to this paper.

Prior Presentation Aspects of this study were presented at the Annual Conference of the GMA (Gesellschaft für Medizinische Ausbildung/German Association for Medical Education) in 2017 in Münster, Germany.

Electronic supplementary material The online version of this article (https://doi.org/10.1007/s11606-019-05420-w) contains supplementary material, which is available to authorized users.

Received December 11, 2018

Revised July 16, 2019

Accepted September 18, 2019

Published online December 10, 2019 compared with the control group ( $d$ between 0.91 and $2.04(p<0.001))$.

CONCLUSIONS: Our results show that an integrated curriculum encompassing $\mathrm{COI}$ and risk communication leads to a large and sustainable increase in risk communication performance. We interpret the large effect sizes to be a result of the integration of topics that are usually taught separately, leading to a more effective organization of knowledge.

Trial Registration: The trial is registered in the International Clinical Trials Registry with the trial number DRKS00010890.

KEY WORDS: Shared decision-making; Risk communication; Conflict of interest; Medical education.

J Gen Intern Med 35(2):473-80

DOI: $10.1007 / \mathrm{s} 11606-019-05420-w$

(C) The Author(s) 2019

\section{INTRODUCTION}

Risk communication is a core aspect of a physician's work and a fundamental prerequisite for successful shared decision-making. ${ }^{1-3}$ However, risk communication is difficult because it requires not only a precise understanding of the harms and benefits of an intervention-whether diagnostic or therapeutic - but also the communicative skills to communicate these risks in a way that is understandable for patients. Studies show that many physicians are not up to the challenge. ${ }^{4-8}$

For one, studies suggest that many physicians cannot accurately interpret statistics commonly used to describe effects of screening and therapeutic interventions; some have called this "statistical illiteracy." ${ }^{, 7}$ For example, many physicians rely on the wrong statistical parameters to judge the effect of screenings for common cancers ${ }^{6}$ and are not able to explain basic statistic concepts such as absolute or relative risk reduction. ${ }^{7}$ Conflicts of interest (COI) resulting from interactions with the pharmaceutical industry further impede the interpretation of risks: they lead to a biased view on risk information as well as a biased presentation of scientific data in information 
brochures and scientific publications. ${ }^{9-11}$ Physicians thus need to avoid such conflicts or manage them professionally to avoid bias. Yet data from the Physician Payments Sunshine Act as well as surveys among physicians show that interactions with pharmaceutical companies continue to be pervasive. ${ }^{12-14}$

According to our literature search and knowledge from a curricular mapping project, most aspects of risk communication are being taught in medical school- however, they are taught separately. ${ }^{15}$ Some curricula on the topics have been published, ${ }^{16-18}$ but no integrated curriculum encompassing all aspects important for risk communication exists in the literature. We thus hypothesize that an integration of the relevant topics - basic statistics, bias detection, professional management of COI, and communication skills - is necessary to improve physicians' risk communication competence by improving knowledge organization, facilitating knowledge transfer into practice, and emphasizing the importance of basic statistics and professionalism for the treatment quality of patients. We developed an integrated curriculum covering these topics and choosing didactic methods primarily based on adult learning theory. ${ }^{19}$ The objective of this study was to evaluate the effects of this curriculum on the participants' risk communication performance.

\section{METHOD}

\section{Ethics Review}

This study received a positive ethics review from the two responsible ethics committees for Mainz and Heidelberg (Ethik-Kommission der Ärztekammer Rheinland-Pfalz, case number 837.053.16 (10372); and Ethikkommission der Medizinischen Fakultät Heidelberg, case number S-314/2016)

\section{Design and Setting}

This was a rater-blind randomized controlled trial conducted from October 2016 to June 2017 at two German academic medical centers (Mainz and Heidelberg). Eligible for participation were all medical students in their fourth and fifth year at the two universities. All participants had had training in statistics and basic communication skills. Each student who completed the entire study received a cash incentive of $100 €$.

\section{Sample Size}

It was calculated that a sample size of 60 participants ( 30 per group) was necessary to guarantee a power of 0.85 to detect an effect size of 0.8 standard deviations regarding the primary outcome (risk communication performance as measured in a video-observed structured clinical examination (VOSCE), see below).

\section{Procedure}

Participating students provided informed consent before completing a baseline assessment consisting of a VOSCE as well as a questionnaire (details see below). The students were then randomized 1:1 to the intervention or control group. After receiving the respective intervention, participants completed a similar assessment twice more: once up to 2 weeks after the intervention (post-test) and once $30( \pm 1)$ weeks later (followup).

\section{Randomization and Blinding}

Randomization to the two groups was stratified by knowledge (see below, "Secondary outcome measures") at baseline. ${ }^{20}$ The randomization sequence was generated by the IMBEI in Mainz. Participants could not be blinded to the allocation because of the nature of the intervention. However, raters and standardized patients (SP) were blinded to the allocation of the participants.

\section{Interventions}

The intervention group received an integrated curriculum developed based on a literature review and expert opinions (see online Appendix Table 1 for an overview of curriculum content and methods). The process for the development of the curriculum was based on the six-step approach described by Kern et al. ${ }^{21}$ For the choice of methods, we used principles of adult learning theory and integrated activities in the active mode of learning according to the "ICAP hypothesis" and used the concept of deliberate practice to design practice sessions. ${ }^{19,} 22,23$

A first version of the curriculum was piloted with 13 medical students in Heidelberg. The curriculum was then adjusted according to feedback from the participants. The final curriculum covered the most essential statistic concepts to judge the efficacy and risks of treatment options and screenings, theoretical and practical skills in risk communication, and an overview of relevant $\mathrm{COI}$ in health care such as sponsorship of research by industry or acceptance of personal gifts, how they may bias the interpretation of risk information, and how COI can be managed to avoid bias (see online Appendix Table 1 for more detail). In all, the course was taught three times in November and December of 2016. The control group received a course manual that was adapted from existing lecture notes from separately taught mandatory courses on communication, statistics, and epidemiology at the Universities of Heidelberg and Mainz ("teaching as usual"); it did not contain information on conflicts of interest, as these are currently not explicitly taught. Participants in both control and intervention groups had participated in the courses prior to participation in our study. Participants in the control group were instructed to revisit the material using our adapted course manual before participating in the post-test (Summary of course manual in online Appendix Table 2).

\section{Primary Outcome Measure}

The primary outcome measure was the change in risk communication performance of the students, measured in a 
VOSCE. ${ }^{24}$ It consisted of two consultations in which the students were asked to communicate to an SP the risks regarding a therapeutic or screening intervention, respectively (see online Appendix 1 for further information). An hour prior to the consultation, students were given informational material on the respective intervention that showed a bias toward the intervention. The consultations were video-taped and rated using an adapted version of the rating scale developed by Han et al., ${ }^{18}$ which consists of 20 items rating risk communication process (RCP), i.e., generic communication skills, and risk communication content (RCC), i.e., the key risk information being communicated. Students could score a maximum possible of 120 points for the two consultations, 72 for risk communication process, and 48 for risk communication content (see online Appendix Table 3 for a list of items on the scale and online Appendix 2 for more detail on the process of adapting the scale as well as scoring details).

Each video was rated independently by two raters. Raters were trained to use the scale by ND and CK. Inter-rater reliability for the rating of the videos was good to excellent with an ICC of 0.884 (CI 0.794 to 0.935 ). For the final analysis, means of the two ratings were used.

\section{Secondary Outcome Measures}

Secondary outcomes were changes in knowledge, attitudes, professionalism regarding $\mathrm{COI}$, frequency of interactions with the pharmaceutical industry, and self-assessed interest, knowledge, and competence.

Knowledge regarding risk communication and COI was assessed in a 30-item multiple choice questionnaire. Attitudes regarding COI were assessed in a 10-item questionnaire adapted from Sierles et al. for the situation in Germany, ${ }^{25,} 26$ from which a skepticism score was calculated where higher scores indicate higher skepticism. ${ }^{25}$ Professionalism regarding the management of COI was assessed using a situational judgment test (SJT) encompassing five scenarios involving a $\mathrm{COI}$ and five possible ways to behave in each. Students could score a maximum of 125 points on the SJT (see online Appendices 3 and 4 for an example of SJT and details of scoring it). Frequency of interactions with the pharmaceutical industry was assessed using a 12-item questionnaire regarding six different types of interactions where students were asked to name the number of times they had been offered or had engaged in this interaction within the last 6 months. Selfassessed interest, knowledge, and competence were assessed using an 11-item questionnaire that was adapted from Brown et al. ${ }^{27}$

\section{Data Analysis}

Data were analyzed using SPSS 23. To test for group differences between the control and intervention groups regarding continuous outcome measures, two-tailed $t$ tests for independent variables were used and Cohen's $d$ calculated. Effect sizes were only calculated for those participants that participated in the respective assessments (post-test/follow-up). A $p<0.05$ was regarded to be significant for the primary outcome. Results are reported as Cohen's $d$ with 95\% confidence interval. The McNemar test was used to test for a bias blind spot. To assess the success of the rater training and the inter-rater reliability for the VOSCE within the study, the average measures, absolute agreement, and two-way random effects ICC were calculated.

\section{RESULTS}

\section{Participants}

Figure 1 details the recruitment of participants. Sixty-three participants were randomized; they had a mean age of 25.7 (SD 3.6), 46/63 (73\%) were female, and on average, they were in their 9th semester of study (8.8; SD 1.3). In the control group, participants also had a mean age of 25.7 (SD 3.7), 25/ $32(78 \%)$ were female, and they were in their 9 th semester of study (8.8; SD 1.1). In the intervention group, participants had a mean age of 25.6 (SD 3.6), 21/31 (68\%) were female, and they were in their 9th semester of study (8.9; SD 1.5) (see Tables 1 and 2 for baseline results for primary and secondary outcomes).] $\rightarrow$

\section{Primary Outcome}

Table 1 gives an overview of the results of risk communication performance. The change in risk communication performance compared with that in baseline was significantly larger in the intervention group for both the post-test and the follow-up with a Cohen's $d$ of 2.35 (CI 1.62 to 3.01, $p<0.01$ ) and 1.83 (CI 1.13 to $2.47, p<0.01$ ), respectively. The difference between the two groups thus persisted until follow-up, though it narrowed slightly (see Fig. 2 for a graphic representation). In Germany, a criterion-based passing score is usually set at $60 \%$ of the full score. Assuming this as a passing score, 42.9\% (12/ 28 ) of the intervention group would have passed the VOSCE at post-test and $40.7 \%(11 / 27)$ at the follow-up, while none of the control group participants would have passed at either time point.] $\rightarrow$

\section{Secondary Outcomes}

Table 2 gives an overview of the secondary outcomes regarding knowledge, attitudes, and professionalism regarding COI. Data from the self-assessment questionnaire is presented in online Appendix Table 4.

\section{Knowledge}

Increase in knowledge was larger in the intervention than in the control group $(d=2.04$ (CI 1.37 to $2.65 ; p<0.01)$ at posttest and 0.91 (CI 0.32 to $1.47 ; p<0.01$ ) at follow-up). Assuming the abovementioned passing score of $60 \%$, at post-test, $27 / 29$ (93.1\%) of the intervention group and 16/27 

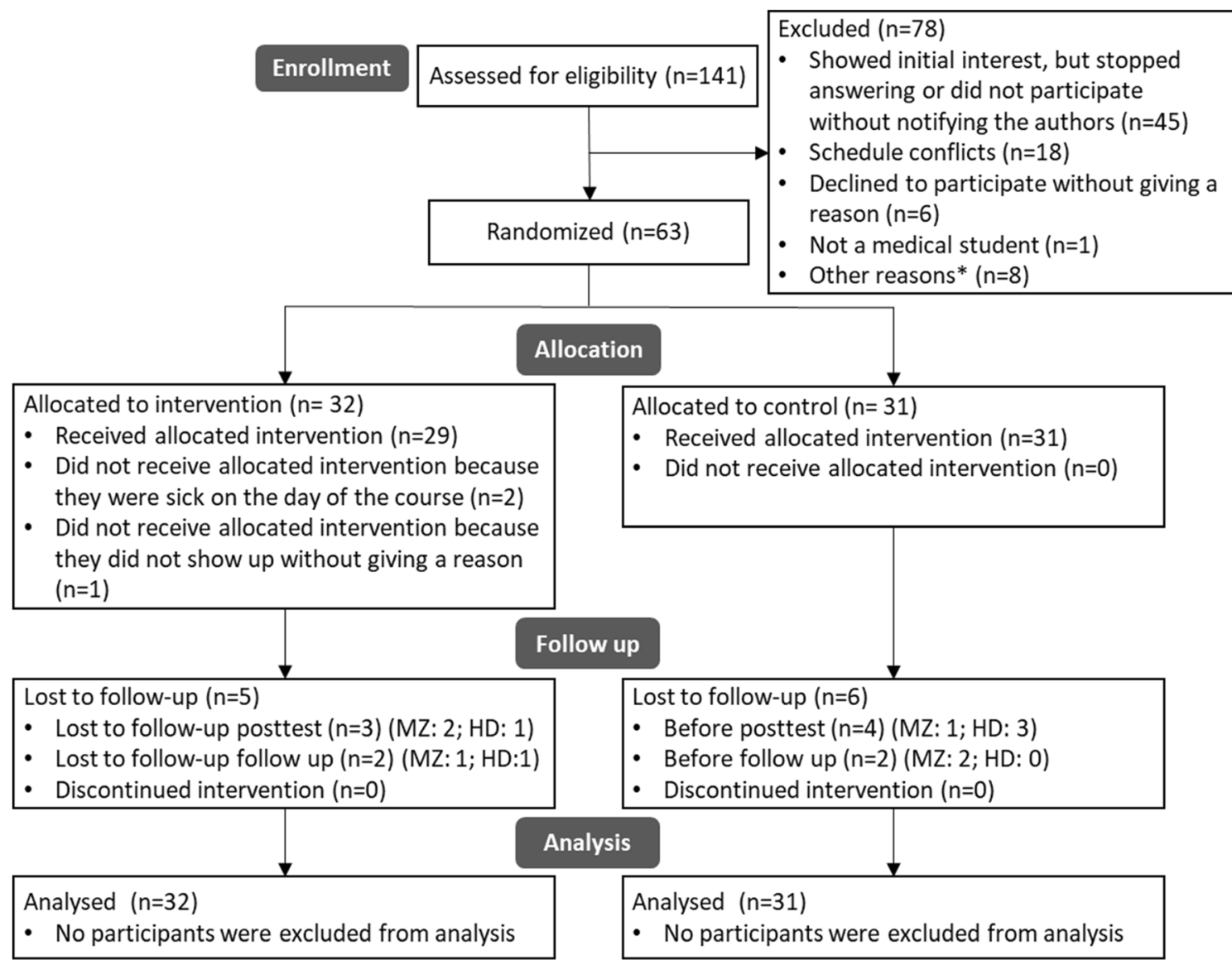

*Trial would take up too much time $(n=4)$, health issues $(n=2)$, change in university $(n=1)$, study abroad during trial $(n=1)$

Figure 1 Recruitment of participants.

Table 1 Risk Communication Performance

\begin{tabular}{|c|c|c|c|c|c|}
\hline Parameter & Baseline & Post-test & $\Delta$ (post-test) & Follow-up & $\Delta$ (follow-up) \\
\hline \multicolumn{6}{|l|}{ Risk communication performance } \\
\hline Intervention group mean (SD) & $48.36(7.51)$ & $70.07(11.8)$ & $21.71(10.24)$ & $\begin{array}{l}68.46 \\
(10.67)\end{array}$ & $19.96(10.46)$ \\
\hline Control group mean (SD) & $49.65(8.12)$ & $\begin{array}{l}50.74 \\
(7.23)\end{array}$ & $0.98(6.81)$ & $52.26(5.59)$ & $3.14(7.12)$ \\
\hline $\begin{array}{l}\text { Difference between intervention } \\
\text { and control }(95 \% \mathrm{CI} ; p)\end{array}$ & - & - & $20.73(15.9$ to $25.56 ;<0.001)$ & - & $16.82(11.49$ to $22.16 ;<0.001)$ \\
\hline Cohen's $d(95 \% \mathrm{CI})$ & - & - & $2.35(1.62$ to 3.01$)$ & - & $1.83(1.13$ to 2.47$)$ \\
\hline \multicolumn{6}{|l|}{ Risk communication process } \\
\hline Intervention group mean (SD) & $44.76(5.49)$ & $\begin{array}{l}49.34 \\
(5.70)\end{array}$ & $4.59(5.83)$ & $50.39(4.13)$ & $5.43(6.91)$ \\
\hline Control group mean (SD) & $44.71(6.77)$ & $\begin{array}{l}45.26 \\
(5.74)\end{array}$ & $0.44(5.41)$ & $46.31(3.98)$ & $1.45(5.03)$ \\
\hline $\begin{array}{l}\text { Difference between intervention } \\
\text { and control means (95\% CI; } p \text { ) }\end{array}$ & - & - & $4.15(1.06$ to $7.24 ; 0.01)$ & - & $3.98(0.39$ to $7.57 ; 0.03)$ \\
\hline Cohen's $d(95 \% \mathrm{CI})$ & - & - & $0.74(0.17$ to 1.28$)$ & - & $0.64(0.05$ to 1.21$)$ \\
\hline \multicolumn{6}{|l|}{ Risk communication content } \\
\hline Intervention group mean (SD) & $3.60(2.05)$ & $\begin{array}{l}20.73 \\
(8.44)\end{array}$ & $17.12(7.70)$ & $18.07(9.10)$ & $14.54(8.34)$ \\
\hline Control group mean (SD) & $4.94(4.54)$ & $5.48(4.20)$ & $0.54(3.27)$ & $5.95(3.38)$ & $1.69(4.33)$ \\
\hline $\begin{array}{l}\text { Difference between intervention } \\
\text { and control means }(95 \% \mathrm{CI} ; p)\end{array}$ & - & - & $16.58(13.25$ to $19.91 ;<0.001)$ & - & $12.85(8.83$ to $16.86 ;<0.001)$ \\
\hline Cohen's $d(95 \% \mathrm{CI})$ & - & - & 2.73 (1.95 to 3.43$)$ & - & $1.86(1.14$ to 2.50$)$ \\
\hline
\end{tabular}

$\Delta$ (post-test), difference between post-test and baseline; $\Delta$ (follow-up), difference between follow-up and baseline; intervention group $n$ at baseline 29 , post-test 29, follow-up 28; control group $n$ at baseline 26, post-test 25, follow-up 21 
Table 2 Secondary Outcomes-Overview

\begin{tabular}{|c|c|c|c|c|c|}
\hline & Baseline & Post-test & $\Delta$ (post-test) & Follow-up & $\Delta$ (follow-up) \\
\hline \multicolumn{6}{|c|}{ Knowledge (multiple choice questionnaire) } \\
\hline Intervention group mean (SD) & $16.63(3.30)$ & $24.00(3.92)$ & $7.52(3.04)$ & $20.93(3.51)$ & $4.46(2.33)$ \\
\hline Control group mean (SD) & $16.35(4.29)$ & $17.93(3.62)$ & $1.96(2.33)$ & $18.38(4.15)$ & $2.08(2.92)^{*}$ \\
\hline $\begin{array}{l}\text { Difference intervention and } \\
\text { control means }(95 \% \mathrm{CI} ; p)\end{array}$ & - & - & $5.55(4.09-7.01 ;<0.001)$ & - & $2.38(0.92-3.84 ;<0.001)$ \\
\hline Cohen's $d(95 \% \mathrm{CI})$ & - & - & $2.04(1.37-2.65)$ & - & $0.91(0.32-1.47)$ \\
\hline \multicolumn{6}{|l|}{ Skepticism (attitude questionnaire) } \\
\hline Intervention group mean (SD) & $0.59(0.17)$ & $0.76(0.14)$ & $0.19(0.17)$ & $0.76(0.17)$ & $0.19(0.20)^{\dagger}$ \\
\hline Control group mean (SD) & $0.51(0.15)$ & $0.54(0.14)$ & $0.03(0.10)$ & $0.54(0.17)$ & $0.02(0.14)$ \\
\hline $\begin{array}{l}\text { Difference intervention and } \\
\text { control means (95\% CI; } p \text { ) }\end{array}$ & - & - & $0.16(0.08-0.23 ;<0.001)$ & - & $0.17(0.07-0.27 ;<0.001)$ \\
\hline Cohen's $d(95 \% \mathrm{CI})$ & - & - & $1.15(0.57-1.69)$ & - & $0.96(0.38-1.52)$ \\
\hline \multicolumn{6}{|l|}{$\begin{array}{l}\text { Professionalism regarding COI } \\
\text { (situational judgment test) }\end{array}$} \\
\hline Intervention group mean (SD) & $66.22(14.02)$ & $84.48(16.00)$ & $18.66(12.06)$ & $85.28(17.11)$ & $19.12(15.75)^{\ddagger}$ \\
\hline Control group mean (SD) & $55.61(15.06)$ & $55.96(16.55)$ & $0.27(7.75)$ & $60.04(21.76)$ & $3.35(12.94)^{8}$ \\
\hline $\begin{array}{l}\text { Difference intervention and } \\
\text { control means }(95 \% \mathrm{CI} ; p)\end{array}$ & - & - & $18.39(12.83-23.94 ;<0.001)$ & - & $15.77(7.36-24.19 ;<0.001)$ \\
\hline Cohen's d (95\% CI) & - & - & $1.79(1.14-2.39)$ & - & $1.09(0.47-1.68)$ \\
\hline
\end{tabular}

$\Delta$ (post-test), difference between post-test and baseline; $\Delta$ (follow-up), difference between follow-up and baseline; intervention group $n$ at baseline 32 , post-test 29, follow-up 28; control group $n$ at baseline 31, post-test 27, follow-up 25; $*_{n}=24,{ }^{\dagger} n=27,{ }^{\star} n=25,{ }^{\boldsymbol{S}_{n}} n=23$

(59.3\%) of the control group would have passed. At followup, $23 / 28(82.1 \%)$ of the intervention group and $17 / 24$ (70.8\%) of the control group would have passed.

\section{Attitudes}

Skepticism increase in the intervention group was larger than in the control group $(d=1.15$ (CI 0.57 to $1.69 ; p<0.01)$ at post-test and 0.96 (CI 0.38 to $1.52 ; p<0.01$ ) at follow-up). Looking at the items individually, the intervention group showed a trend toward more skeptical attitudes that persisted until follow-up in all attitude items. Table 3 shows individual item data for the most relevant attitude items regarding bias detection in risk information.

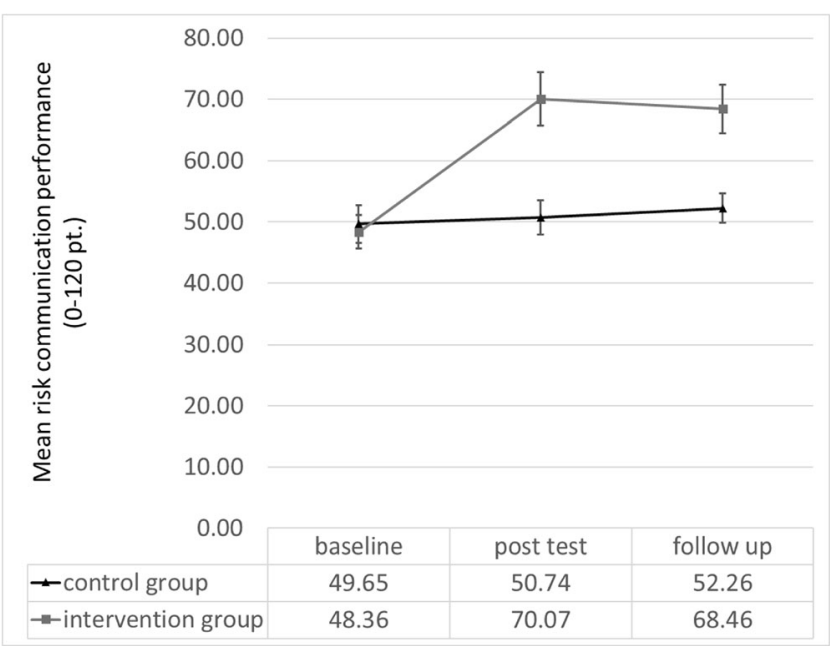

Figure 2 Risk communication performance (error bars denote standard deviation).
At baseline, more participants in both the intervention and the control groups thought that others were more likely to be influenced by gifts from pharmaceutical sales representatives than themselves, which has been described as evidence for a "bias blind spot." 28 At post-test and follow-up, this difference was not seen in the intervention group (see Table 4), while it remained in the control group.

\section{Professionalism Regarding COI}

The improvement in professionalism regarding COI was higher in the intervention group at post-test as well as follow-up with $d=1.79$ (CI 1.14 to $2.39, p<0.01$ ) and 1.09 (CI 0.47 to $1.68, p<0.01$ ), respectively. These results were similarly found for each scenario separately (see online Appendix Table 5).

\section{Acceptance of Gifts}

At baseline, 21\% (13/62) of all participants indicated that they had not interacted with pharmaceutical companies within the last 6 months. This percentage increased to $39.2 \%(20 / 51)$ at follow-up; however, there was no relevant difference between the intervention and control groups (intervention group $40.7 \%$ $(11 / 27)$, control group $37.5 \%(9 / 24))$. Further data on gift acceptance can be found in online Appendix Table 6 .

\section{DISCUSSION}

The integrated curriculum on conflicts of interest and risk communication we developed led to a large, statistically significant increase in risk communication performance of the participants compared with the control group at both post-test 
Table 3 Relevant Individual Item Data for Attitudes on COI (on a Likert Scale from 0 to 3; Scaled so that a higher score signals a more skeptical attitude)

\begin{tabular}{|c|c|c|c|c|c|c|c|c|}
\hline \multirow[t]{2}{*}{ Item } & & \multirow{2}{*}{$\frac{\text { Baseline }}{M(\mathrm{SD})}$} & \multirow{2}{*}{$\begin{array}{l}\text { Post } \\
M(\mathrm{SD})\end{array}$} & \multicolumn{2}{|l|}{$\Delta$ post } & \multirow{2}{*}{$\frac{\text { Follow-up }}{M(\mathrm{SD})}$} & \multicolumn{2}{|l|}{$\Delta$ follow-up } \\
\hline & & & & $M(\mathrm{SD})$ & $p$ & & $M(\mathrm{SD})$ & $p$ \\
\hline Materials from a pharmaceutical & Int & $1.63(0.71)$ & $2.38(0.56)$ & $0.79(0.78)$ & $<0.01$ & $2.26(0.71)$ & $0.70(0.87)$ & $<0.01$ \\
\hline company are helpful to inform & Con & $1.52(0.72)$ & $1.33(0.55)$ & $-0.26(0.90)$ & 0.15 & $1.20(0.71)$ & $-0.48(0.77)$ & $<0.01$ \\
\hline oneself about new drugs. & $\begin{array}{l}\text { Diff. between } \\
\text { Int and Con }\end{array}$ & - & - & 1.05 & $<0.01$ & - & 1.18 & $<0.01$ \\
\hline Most CME events or grand & Int & $1.75(0.67)$ & $2.17(0.60)$ & $0.45(0.74)$ & $<0.01$ & $1.96(0.65)$ & $0.30(0.82)$ & 0.073 \\
\hline rounds sponsored by & Con & $1.19(0.60)$ & $1.30(0.47)$ & $0.15(0.66)$ & 0.26 & $1.44(0.77)$ & $0.28(0.79)$ & 0.09 \\
\hline $\begin{array}{l}\text { pharmaceutical companies } \\
\text { are helpful and informative. }\end{array}$ & $\begin{array}{l}\text { Diff. between } \\
\text { Int and Con }\end{array}$ & - & - & 0.3 & 0.12 & - & 0.016 & 0.94 \\
\hline CME events or grand & Int & $2.56(0.50)$ & $2.83(0.38)$ & $0.24(0.69)$ & 0.07 & $2.65(0.75)$ & $0.08(0.80)$ & 0.63 \\
\hline rounds sponsored by & Con & $2.42(0.67)$ & $2.56(0.51)$ & $0.15(0.60)$ & 0.21 & $2.48(0.59)$ & $0.08(0.70)$ & 0.57 \\
\hline $\begin{array}{l}\text { pharmaceutical companies are } \\
\text { usually biased in favor of the } \\
\text { company's product. }\end{array}$ & $\begin{array}{l}\text { Diff. between } \\
\text { Int and Con }\end{array}$ & - & - & 0.093 & 0.59 & - & 0 & 0.99 \\
\hline It is sometimes acceptable & Int & $2.09(0.86)$ & $2.45(0.74)$ & $0.41(0.82)$ & 0.01 & $2.56(0.58)$ & $0.59(0.84)$ & $<0.01$ \\
\hline for medical students to accept & Con & $1.81(1.08)$ & $1.74(0.90)$ & $-0.11(0.97)$ & 0.56 & $1.92(0.78)$ & $0.08(1.01)$ & 0.60 \\
\hline gifts or lunch from & Diff. between & - & - & 0.52 & 0.03 & - & 0.51 & 0.057 \\
\hline $\begin{array}{l}\text { pharmaceutical companies because } \\
\text { pharmaceutical companies have } \\
\text { minimal influence on students. }\end{array}$ & Int and Con & & & & & & & \\
\hline
\end{tabular}

Int intervention group, Con control group, $\Delta$ change within group from baseline

and follow-up 30 weeks later. In addition, the intervention group showed increased knowledge regarding both risk communication and COI and a change in attitudes toward more skepticism toward interactions with pharmaceutical companies as well as improved intentions of managing COI in a way that reduces their risk of bias. However, there was no change in acceptance of gifts or attendance of sponsored events. At follow-up, differences between the two groups decreased slightly for all measures. This was especially pronounced for the $\mathrm{MC}$ knowledge exam, where the intervention group score declined while the control group score increased slightly. Risk communication performance and attitude items, however, were relatively stable.

The change in risk communication competence is generally in line with the results of one other study evaluating a curriculum on the topic. In this single blind controlled trial, the intervention group also had significantly better scores for objective risk communication competence (content as well as process) than the control group. ${ }^{18}$ Regarding the baseline skepticism, students in our study were comparable with

Table 4 Bias Blind Spot

\begin{tabular}{llll}
\hline \hline & Baseline & Post-test & Follow-up \\
\hline Intervention group, $n$ & 32 & 29 & 26 \\
Influence on me* & $14(43.8 \%)$ & $23(79.3 \%)$ & $24(92.3 \%)$ \\
Influence on others $^{\dagger}$ & $21(65.6 \%)$ & $25(86.2 \%)$ & $24(92.3 \%)$ \\
$p$ & 0.039 & 0.5 & 1 \\
Control group, $n$ & 31 & 27 & 25 \\
Influence on me* & $12(38.7 \%)$ & $14(51.9 \%)$ & $14(56.0 \%)$ \\
Influence on others & $21(67.7 \%)$ & $20(74.1 \%)$ & $19(760 \%)$ \\
$p$ & 0.004 & 0.031 & 0.13 \\
\hline
\end{tabular}

*Agreement with the statement "Accepting gifts or food from a drug rep increases the likelihood that I will later prescribe the drugs of that company"

FAgreement with the statement "Accepting gifts or food from a drug rep increases the likelihood that my fellow students will later prescribe the drugs of that company" previous German and international studies, albeit slightly more skeptical. ${ }^{25,}{ }^{26}$ In studies on curricula regarding COI, similar changes in attitude were found as in this study. However, none of these had a comparable follow-up and effects seen were usually somewhat smaller or less consistent than in this study. ${ }^{16}$ To our knowledge, no study has assessed the management of COI by students using an SJT. Previous studies assessing the effect of curricula on accepting gifts have had contradictory results. ${ }^{16}$

We suspect that the large effects we found are due to the integration of topics that are usually taught separately. This is supported by the fact that all the students had had courses on almost all of the topics covered in our curriculum and still showed a large learning gain. In our view, this cannot be exclusively due to the coverage of novel content, because only very little content, mostly pertaining to conflicts of interest, was taught to the intervention but not the control group. One of the reasons why integrated curricula may lead to a larger learning effect is that they support a knowledge organization by students that is better matched to the tasks that are required of them. ${ }^{29}$ When topics are taught separately, students organize knowledge around separate categories and may fail to make connections for tasks that require incorporating different areas of expertise. Teaching the topics together with a clear structure denoting how the topics are relevant to the tasks may thus lead to a larger learning gain. Additionally, following adult learning theory, the practical exercises based on situations encountered during clinical practice underscore the relevance of topics to the participants' daily lives, leading to a larger motivation to learn. ${ }^{19}$ Despite the large learning gains, only $40 \%$ of students in the intervention group would have passed the VOSCE when applying a criterion-based passing score of $60 \%$. We think this may be due to a combination of factors: our rating scale is not externally validated, so it is unclear which score corresponds to a sufficient mastering of 
the task; students may not have prepared for the formative assessment within our study as intensively as they would have for a grade-relevant exam; and finally, the students may have needed more time to master this highly complex task.

In addition, the gain in risk communication competence was enduring over the 30-week follow-up, unlike the knowledge gain. Possibly, risk communication is a form of procedural knowledge less prone to decline. In addition, the intense ("deliberate") practice of this skill during the curriculum using both role play and training with SPs could explain that this competence was more enduring than the declarative knowledge needed for the MC exam. ${ }^{23}$

It is unclear why the marked change in attitudes as well as behavioral intent did not translate to a change in behavior regarding accepted gifts or attended sponsored events. This could be due to environmental factors, conforming with the social cognitive theory of behavior. ${ }^{30}$ Furthermore, the prediction of behavior from attitudes is generally difficult. ${ }^{31,32}$ Lastly, our study was only powered to detect a difference in the primary outcome, possibly explaining why we did not find a difference regarding gift acceptance.

This study had several strengths. One was the meticulous development process for the integrated curriculum, which resulted in a well-crafted course with a high acceptance by the participants. Methodically, the randomized controlled design is a major strength of this study. It is the first study to investigate the effects of a curriculum on COI or risk communication with such a design. ${ }^{16}$ The long follow-up period is also an advantage compared with other trials of curricula covering similar topics. A weakness of our study is that the evaluation instruments were not formally validated. However, they had been piloted and the rating scale for the VOSCE showed a good internal consistency and high inter-rater reliability.

The fact that most of the individual topics necessary for risk communication had already been taught to participants previously supports our hypothesis that the large learning gains we found are mostly due to our method of integration of topics rather than due to the teaching of previously unknown subject matter. Consequently, an entrustable professional activity testing clinical decision-making under the consideration of COI has been introduced as a requirement for the licensing examinations in Germany following the results of this study. However, our study was not designed to test which elements of the curriculum were responsible for the large effects. Further studies are needed to identify whether our hypothesis that integration is the reason for the large effects holds true and to demonstrate the implementation at other universities is feasible and leads to comparably strong effects as seen in our study.

Acknowledgments: We thank Prof. Paul Han (MD, MA, MPH) for guidance regarding the risk communication scale as well as supply of materials used in the curriculum; Prof. Dr. phil. Gerd Gigerenzer, Prof. Dr. med. Dr. phil. Dipl.-Psych. Martin Härter, MPH, Dr. rer. nat. Felix Rebitschek, PD, Dr. rer. nat. Dipl.-Phys. Cord Spreckelsen, and Dr. med. Peter Tinnemann for input on the curriculum as well as study design; Stephanie Seidemann for support during the pilot phase of the project; Dr. Anke Hollinderbäumer, MME, for consultations during the planning of the study; Prof. Dr. med. Wolfgang Herzog for support of the study; PD Dr. med. Jobst-Hendrik Schultz for allowing us to adapt the script for the communication course in Heidelberg; the IMBEI in Mainz for statistical consultations and allowing us to adapt the script on medical statistics; Dr. med. Holger Buggenhagen and Thomas Nowak from the "Lernklinik" in Mainz for providing the space to teach the curriculum as well as support in recruiting standardized patients; Andrea Schaal-Ardicoglu for training the standardized patients; and Katharina Heese, Linda Malm, Oskar Buescher, and Tina Boldt for rating the videos.

Corresponding Author: Jana Jünger, Prof; IMPP - German Institute for Medical and Pharmaceutical Examinations, Postfach 252855015 , Mainz, Germany (e-mail: JJuenger@impp.de).

Funding Information This study was funded by a grant from the Volkswagen Foundation, grant no. 88574 to K.L., N.D., and J.J.

Data availability The data sets analyzed during this study are available from the corresponding author upon reasonable request.

\section{Compliance with Ethical Standards:}

Conflict of Interest: $C K$ is a member of MEZIS, the German "No free lunch"-association. ND, JW, NDe, EG, SW, MS, and FB have nothing to disclose. KL declares that he did not receive any personal honoraria since 2008 for advisory board activities, CME activities, talks, or other activities from pharmaceutical companies or medical device manufacturers. For conducting drug research within his clinical study center, several co-workers of his clinic received grants during the last 3 years from Roche Pharma, Hoffmann La Roche, D\&A Pharma, Boehringer Ingelheim Pharma GmbH \& Co. KG, Pfizer Pharma GmbH, and Janssen-Cilag GmbH (deposited at third-party accounts of the clinic). He has been a member of MEZIS e.V. since 2007, and since 2014, he is the chairman of the Committee of Experts for Transparency and Independence of the German Medical Association. He receives honoraria from the Academy for Medical Advanced Training of RhinelandPalatinate for conducting CME courses in psychiatry and psychotherapy and is the director of LIBERMED, which offers CME courses in various medical disciplines that are independent from the pharmaceutical industry. JJ has nothing to disclose.

Open Access This article is distributed under the terms of the Creative Commons Attribution 4.0 International License (http:// creativecommons.org/licenses/by/4.0/), which permits unrestricted use, distribution, and reproduction in any medium, provided you give appropriate credit to the original author(s) and the source, provide a link to the Creative Commons license, and indicate if changes were made.

\section{REFERENCES}

1. Makoul G, Clayman ML. An integrative model of shared decision making in medical encounters. Patient Educ Couns 2006;60(3):301-12.

2. Audrey S, Abel J, Blazeby JM, Falk S, Campbell R. What oncologists tell patients about survival benefits of palliative chemotherapy and implications for informed consent: qualitative study. BMJ. 2008;337:a752.

3. Gigerenzer G. Towards a paradigm shift in cancer screening: informed citizens instead of greater participation. BMJ. 2015;350:h2175.

4. Gaissmaier W, Anderson BL, Schulkin J. How Do Physicians Provide Statistical Information about Antidepressants to Hypothetical Patients? Med Decis Mak 2014;34(2):206-15.

5. Gigerenzer G, Gaissmaier W, Kurz-Milcke E, Schwartz LM, Woloshin S. Helping Doctors and Patients Make Sense of Health Statistics. Psychol Sci Public Interest J Am Psychol Soc 2007;8(2):53-96.

6. Wegwarth O, Schwartz LM, Woloshin S, Gaissmaier W, Gigerenzer G. Do physicians understand cancer screening statistics? A national survey of primary care physicians in the United States. Ann Intern Med 2012;156(5):340-349.

7. Young JM, Glasziou P, Ward JE. General practitioners' self ratings of skills in evidence based medicine: validation study. BMJ. 2002;324(7343):950-1.

8. Gigerenzer G. Breast cancer screening pamphlets mislead women. BMJ 2014;348:g2636. 
9. Wang AT, McCoy CP, Murad MH, Montori VM. Association between industry affiliation and position on cardiovascular risk with rosiglitazone: cross sectional systematic review. BMJ. 2010;340:c1344.

10. Dunn AG, Arachi D, Hudgins J, Tsafnat G, Coiera E, Bourgeois FT. Financial conflicts of interest and conclusions about neuraminidase inhibitors for influenza: an analysis of systematic reviews. Ann Intern Med 2014;161(7):513-8.

11. Spurling GK, Mansfield PR, Montgomery BD, Lexchin J, Doust J, Othman $\mathrm{N}$, et al. Information from pharmaceutical companies and the quality, quantity, and cost of physicians' prescribing: a systematic review. PLoS Med 2010;7(10):e1000352.

12. Lieb K, Brandtönies S. A survey of German physicians in private practice about contacts with pharmaceutical sales representatives. Dtsch Ärztebl Int 2010; 107(22):392-8

13. Tringale KR, Marshall D, Mackey TK, Connor M, Murphy JD, HattangadiGluth JA. Types and Distribution of Payments From Industry to Physicians in 2015. JAMA. 2017;317(17):1774-84.

14. Lieb K, Scheurich A. Contact between Doctors and the Pharmaceutical Industry, Their Perceptions, and the Effects on Prescribing Habits. PLoS One 2014 16;9(10).

15. Lammerding-Koeppel M, Fritze O, Giesler M, Narciss E, Steffens S, Wosnik A, et al. Benchmarking for research-related competencies - a curricular mapping approach at medical faculties in Germany. Med Teach 2018;40(2):164-73.

16. Weißkircher J, Koch C, Dreimüller N, Lieb K. Conflicts of Interest in Medicine. A Systematic Review of Published and Scientifically evaluated Curricula. GMS J Med Educ [Internet]. 2017 15 [cited 2019 Aug 19];34(3). Available from: https://www.ncbi.nlm.nih.gov/pmc/articles/PMC5569982/

17. Elwyn G. Achieving involvement: process outcomes from a cluster randomized trial of shared decision making skill development and use of risk communication aids in general practice. Fam Pract 2004;21(4):337-46.

18. Han PKJ, Joekes K, Elwyn G, Mazor KM, Thomson R, Sedgwick P, et al. Development and evaluation of a risk communication curriculum for medical students. Patient Educ Couns 2014;94(1):43-9.

19. Kaufman DM. ABC of learning and teaching in medicine: Applying educational theory in practice. BMJ. 2003;326(7382):213.
20. Hailikari T, Katajavuori N, Lindblom-Ylanne S. The relevance of prior knowledge in learning and instructional design. Am J Pharm Educ 2008;72(5): 113.

21. Kern D, Thomas P, Howard D, Bass E. Curriculum Development for Medical Education. A Six-Step-Approach. Baltimore: The John Hopkins University Press; 1998.

22. Chi MTH, Wylie R. The ICAP Framework: Linking Cognitive Engagement to Active Learning Outcomes. Educ Psychol 2014;49(4):219-43.

23. Ericsson KA. Acquisition and maintenance of medical expertise: a perspective from the expert-performance approach with deliberate practice. Acad Med J Assoc Am Med Coll 2015;90(11):1471-86.

24. Kiehl C, Simmenroth-Nayda A, Goerlich Y, Entwistle A, Schiekirka S, Ghadimi BM, et al. Standardized and quality-assured video-recorded examination in undergraduate education: informed consent prior to surgery. J Surg Res 2014;191(1):64-73.

25. Sierles FS, Brodkey AC, Cleary LM, McCurdy FA, Mintz M, Frank J, et al. Medical students' exposure to and attitudes about drug company interactions: a national survey. JAMA. 2005;294(9):1034-42.

26. Lieb K, Koch C. Medical students' attitudes to and contact with the pharmaceutical industry: a survey at eight German university hospitals. Dtsch Arztebl Int 2013;110(35-36):584-90.

27. Braun E, Gusy B, Leidner B, Hannover B. Das Berliner Evaluations instrument für selbsteingeschätzte, studentische Kompetenzen (BEvaKomp). In: Diagnostica. 2008. p. 30-42.

28. Pronin E, Kugler MB. Valuing thoughts, ignoring behavior: The introspection illusion as a source of the bias blind spot. J Exp Soc Psychol 2007;43(4):565-78.

29. Ambrose SA, Bridges MW, DiPietro M, Lovett MC, Norman MK. How learning works: Seven research-based principles for smart teaching. John Wiley \& Sons; 2010.

30. Bandura A. Social cognitive theory: An agentic perspective. Asian J Soc Psychol 1999;(2):21-41.

31. Kim M-S, Hunter J. Attitude-Behavior Relations: A Meta-Analysis of Attitudinal Relevance and Topic. J Commun 1993;43(1):101-42.

32. Kim M-S, Hunter J. Relationships Among Attitudes, Behavioral Intentions, and Behavior: A Meta-Analysis of Past Research, Part 2. Commun Res 1993;20(3):331-64.

Publisher's Note Springer Nature remains neutral with regard to jurisdictional claims in published maps and institutional affiliations. 